\title{
Policy Makers and Their Communication Strategy
}

\author{
Giulia Netti ${ }^{1}$ \\ ${ }^{1}$ Department of Economics, Lum Jean Monnet University, Casamassima (Ba), Italy \\ Correspondence: Giulia Netti, PhD in the Economics and Management of Natural Resource, Department of \\ Economics, Lum Jean Monnet University, Casamassima (Ba), Italy.
}

Received: March 18, 2020

Accepted: April 8, 2020

Online Published: April 16, 2020

doi:10.5430/ijba.v11n3p1

URL: https://doi.org/10.5430/ijba.v11n3p1

\begin{abstract}
This paper wants to verify how politicians move within different communication channels, both in traditional networks (i.e., exploitative communications) and social network (i.e., explorational communications). The study of the role of these two forms of communication may ameliorate the current understanding of how politicians communicate with citizens; and also it aims at examining the relationship between traditional forms of communication used by politicians (here intended as the use of a personal website) and the use of social network (here measured in terms of the number of posts on Twitter) in influencing the tendency to be followed on social networks.

This research aims to demonstrate that the choice of politicians in adopting both exploitative communication and explorational communication is more effective and efficient than choosing to adopt a single strategy.

It is made two different study. In the study 1, we a collected data about votes by section, number elected by section, average voters for the last legislature for each Italian party. Data were extracted from the Minister of Internal Affairs. Five models were created and they are estimated for the most important Parties of the last legislature in which reliable data exist for votes by section, number elected by section, average voters, Followers on Facebook, Likes Instagram, Likes Facebook, Followers on Instagram, Facebook Profile and Followers on Twitter.

The supplementary analysis is further test of our hypothesis. We a collected data concerning traditional channels - in particular the use of institutional websites and personal websites - and data relating to social media in particular, were collected for each individual parliamentarian (deputies and senators).

Specifically, a moderation analysis was conducted in which followers on Twitter served as the dependent variable. The results support our hypothesis.

This study has found important and significant results compared to the use of social media by Italian politicians. However, it has many potentialities to explore.
\end{abstract}

Keywords: exploitative communication, explorational communication, Italian politicians, ambidexterity

\section{Introduction}

Since the beginning of the post-industrial society (Lyotard, 2002), the production system has focused on "information processing, on the strategic role of theoretical knowledge as a basis for technological progress" (Garagnani, 1987, pp. 135). In this transformation process, communication technologies have assumed a central role, so much that the economy, until then gravitating around material goods, for the first time found itself rotating around intangible assets (Pietrangelo, 2007).

The recent diffusion of computer-mediated communications represents the natural development of these processes of technological transformation and, consequently, of socio-economic ones. With the growing availability of technological tools and infrastructures, there has been a strong increase in the use of virtual places in which society has gradually assumed the connotations of a widespread network, made up of individuals needing to find and recognizing themselves through the frequentation of mainly virtual communities. This has contributed to the explosion of those channels of interaction and those places of sociability that today we call "social networks". They represent virtual platforms within which users can introduce themselves and connect with other people, thus creating online groups (Ellison et al., 2007). Boyd and Ellison (2007) defined sites and social networks as web services that 
allow people to create a public or semi-public profile within a bound system, thanks to the articulation of contact lists and other users within the system itself.

The social network sites have changed and continue to change the way in which it is possible to interact with other individuals, allowing for the use of advanced methods of communication, thanks to the development of a widespread access and a multi-directional transmission of information, according to dynamics that provide for the possibility to send public or private messages, share photos online, and establish and maintain connections with people, known or unknown until then.

As can be imagined, when a society is evolving, even the disciplines studying that society, or that have - in some way - the society as a reference object, are obliged to redefine their interpretive methodologies and paradigms. With regard to other disciplines, also "marketing has faced the difficulty of interpreting and decoding the new postmodern reality" (Cova et al., 2007, pp. 31), with obsolete and inadequate tools; and this because traditional marketing, remaining strongly anchored to the old market concept (Wipperfürth, 2005), was not able to immediately consider the social dimension and the active role of the consumer (Collesei, 2008).

New technologies have contributed to the transformation of places of socialization, as have new dynamics pushed towards the development of concepts capable of grasping the transformations of the subjects involved in the communication and exchange processes. And this is how the economic-relational landscape has registered the entry of new concepts, such as that of "prosumer", capable of giving citizenship to that evolution of the traditional figures of "frequenters" of the market.

Communication is increasingly important for the development of knowledge, information and training. Citizens and politicians are well aware of this, and in recent years they have been fighting through "word of mouth" on all the channels at their disposal (exploitative and explorational communications), trying to capture as much consent from voters as possible and encouraging the still "genuine" generations to take an interest in politics.

This study wants to verify how politicians move within different communication channels, both in traditional networks (i.e., exploitative communications) and social network (i.e., explorational communications). The study of the role of these two forms of communication may ameliorate the current understanding of how politicians communicate with citizens.

\section{Theoretical Background on Social Media Channels}

"Social networks move on two levels": on the one hand, they insist on aspects of "personal identity" (Menduni et al., 2011, pp.359) on the web and on the system of relations between self and others; on the other, they modify the public sphere lending itself to different uses ranging from political communication, to marketing, to the dissemination of opinions, trends and fashions.

Ignoring the world of social networks means ignoring the fact that this tool is indeed used by people to learn about products and services and to promote opinions that can endorse changes in perspective. Companies know this and they use online word of mouth to talk about themselves, trying in some way to control the environment (Vollmer and Precourt, 2008). Obviously, social networks favor the dynamics of word of mouth, as the social networks themselves are a tool of hybrid promotion because they combine the characteristics of traditional communication tools (companies that speak to their audience) and word of mouth (allowing people who compose that audience to talk to each other) (Mangold and Faulds, 2009).

From what has been highlighted so far, it emerges, in line with Goffman's (1986) research, how the changes in the new media involve a change in the habits of the people who use them. The cause of such a change in communication methods is not solely due to the creation of new networks to communicate, but rather the development of new technology and media that cause different types of actions, interactions and social relations (Thompson, 1998). First of all, it should be noted that we are dealing with the dynamics of redefining the concept of space and time (Abruzzese and Mancini, 2007); in fact, in interacting through social networks eliminates the need of participants to be in the same physical place and at the same time as the others. Thompson (1998) identifies three types of interaction that differ from each other according to whether or not they share the same space-time environment: face-to-face interaction, mediated interaction, and quasi-mediated interaction (Thompson, 1998). Mediated interaction, unlike face-to-face interaction, is more ambiguous because it deprives the communicating subject of those significant references that he/she would have in the case of a face-to-face interaction, where metalinguistic codes intervene. In the case of mediated interaction, however, there are applications that allow for the enriching of communication through the use of graphic symbols that replace the missing clues in non-verbal communication, such 
as emoticons (Joseph and Kyle, 2001), or a series of combinations of symbols that represent the different facial expressions, thus enriching the mediated conversation.

Among the various research areas, there are many studies that have investigated and analyzed the behavior of the subjects in their online interaction and communication.

The research by Charlene and Bernoff (2008) has divided people according to the profile they have on their personal pages, identifying seven groups of personalities based on the actions they perform:

- Creators: those who publish content on a blog or web page at least once a month;

- Conversators: those who post and update their status on social media, stimulating discussions and conversations;

- Critics: are those who react to the actions of other users, commenting, voting or modifying on what others publish;

- Collectors: those who select and keep an eye on a series of web pages or blogs, to monitor their contents, receive updates, etc.;

- Sociable: those who actively use social networks;

- Spectators: those who benefit from the contents published by others;

- Inactive: those who do not participate in online activities.

This gives us a glimpse of the possibility that networks of relationships based on personality conjunctures can be established. The panorama of virtual personality construction tools is enriched by a series of attributes coming from the presence of a subject on various social media, including blogs and micro-blogs. Micro-blogging is a platform that combines elements typical of blogs with features of messaging services and social networks. The leader in the field of micro-blogging is the free Twitter platform.

The possibility of being able to create and participate in these transparent, personalized and, in any case, free online communities is one of the advantages offered by these new applications (Urban, 2003), which opens up a new experiential paradigm. Here the panorama opens up on what has been defined as the Web 2.0 Experience (Constantinides, 2004).

This is the convergence of all those non-controllable factors of the web 2.0 that do not concern interactivity with companies, but those applications and dedicated platforms that encourage the aggregation of people: e.g., social networks, blogs, forums, communities, which are gradually being created thanks to networks able to "group" millions of people who exchange information, opinions, news, suggestions and, therefore, influence on any subject or experience produced. Because it is a "spontaneous" exchange of information between individuals, organizations cannot control the flow of information generated by these exchanges that spread like a wildfire in a capillary fashion on different sites and devices.

Social networks integrate the communication strategies offered by the website, proposing themselves as preferential channels for informal and direct communication: talking through a social media is like "talking in front of people" (Conti, 2010). Consequently, as Hyzlett stated, not taking care of one's presence on social networks is like committing commercial suicide. (Cosenza, 2012).

Some scholars (McInnis et al., 1989) have identified three drivers that motivate users to share their know-how: motivation, opportunities, and skills. Motivation is defined as "the stimulus, the urgency, the desire [...] that starts a sequence of events known as behavior" (Bayton, 1985, p. 282), this concept joins with the "concept of involvement" (Nelli and Bensi, 2005); opportunity refers instead to the possibility to "process information" in the form of an image to be shared with other users of the web.

From what has been analyzed up to now, at least two sets of conclusions seem to emerge: the first is socio-economic and the second is socio-cultural. From a socio-economic point of view, the advent of social media has led to the massification of the phenomenon of User Generated Contents (UGC) that has allowed users, prosumers and interactors, to support the activity of traditional content providers and to produce contents for the members of their personal networks, who - in turn - share the information received in other belonging networks, giving rise to what Prunesti (2016, p. 134) called the "long tail of digital communication".

From a socio-cultural point of view, the convergence of all the aforementioned components feeds the hypothesis that the reflection on social networks has reached a point where one has the sensation of being faced with an 
extra-ordinary phenomenon, of unpredictable perspectives, a phenomenon that is self-reproducing exponentially thanks to this very peculiar unpredictability.

The technological innovations still underway form the basis of the development of a "culture of participation", and consequent "participation society" in which, through the web, it is possible to participate in cultural life on a global level, transforming ourselves and our media products in vectors of a collective intelligence that is now the basis of our identity, and defines us far more than traditions, history, social status or even native language as Polish writer Priot Czerski asserts in un his article published in The Atlantic journal.. Paraphrasing Jenkins (2007), it is a sort of "socio-cultural convergence" with respect to which social media have played a facilitating and generative role, configuring themselves both as instruments of division and as artifacts capable of objectifying, translating into practice and spreading new cognitive, relational and organizational models made possible by these specific spaces of the network.

The extraordinary exchange of relationships, information and communication among users of social networks, generated by improbable interactions and unpredictable relationships, as well as giving the sensation of increasing skill and performance, helps to dispel the sense of place and time, feeding the imagery of a man who can finally take possession of the "gift" of ubiquity and multiple intelligence of Gardner (2011), so much as to push some to say that the "crowd" has become "intelligent".

All this has helped to define, what Chieffi et al. affirm (2013) is the "visual drift of the web" that consecrates video as the most widespread media object on the Internet and that meets the maximum interest from users. It is, therefore, possible to obtain discrete popularity by uploading videos to platforms, a measurable feature in terms of views, comments, interactions, shares, insertion in playlists and the possibility to appear among the first search results.

\section{Explorational Communication}

In this study, explorational communication is defined as the ability to communicate through new digital channels, explore the new social media and be able to innovate with them. Social channels such as Facebook, Twitter and Instagram are studied as examples of this. Only these social networks have been taken into account instead of other social networks like LinkedIN, Snapchat etc., since the former are the most used by Italian users (Global Digital Report, 2018).

\subsection{Facebook}

One of the most famous and popular social networking sites is Facebook, created in 2004 by Mark Zuckerberg, then a student at Harvard University, along with some of his college mates, with the aim of "giving people the power to share and make the world more transparent and connected" (Facebook, 2011a, p. 1).

In the scientific field, Facebook has captured the attention of researchers and analysts since its creation. The exorbitant attractiveness that this site has gradually registered, has contributed to baptizing Facebook as a founding instrument of the modern dynamics of social interaction, as well as an unavoidable reality integrating the everyday life of over a billion people (Facebook, 2013b). Despite the current state of Facebook as a site frequented by the most diverse groups of users, recent studies have highlighted a prevalence of young and very young users, even below the minimum age of 13 required by administrators to be able to register on the site, and they even spend more than 2 hours a day on it (Lenhart et al., 2010; Panek et al., 2013; Ryan and Xenos, 2011). The motivations that push so many people to access Facebook have been analyzed, which made it possible to identify in first place among the motivations, the possibility of keeping in contact with other people, especially those that are part of the user's life even in the offline world (Baltaretu and Balaban, 2010; Saleh et al., 2011). Facebook has been able to satisfy many other needs, such as that of belonging (Kim and Lee, 2011; Nadkarni and Hofmann, 2012), increasing the share capital (Ellison et al., 2007; Gonzales and Hancock, 2011; Tazghini and Siedlecki, 2013), meeting new people (Lewis and West, 2009), seeking emotional support (Joinson, 2008), self-presenting and expressing one selves (DeWall et al., 2011; Pempek et al., 2009).

Numerous other researchers have investigated the way in which users present their identity, the disclosure of personal information and aspects related to privacy, also and above all in consideration of the possible risks related to behavior that is considered irresponsible given the situation (Gross and Purchases, 2005; Young and Quan-Haase, 2009).

The exponential implementation of the number of members and visitors has decreed the awareness of Facebook as a socio-economic phenomenon of global reach. This has stimulated the start of much research, among other things aimed at investigating the effects of Facebook on the individual. The latter line of research has, in fact, fueled a debate on the positive effects and possible negative outcomes of Facebook. The scholars are divided among those 
who consider Facebook a means to develop a new form of internet addiction, the "Facebook addiction" (Karaiskos et al., 2010), with negative consequences such as a departure from the world and "real" interactions (Sheldon et al., 2011) and those who underline the positive impact that its use can have on people, in terms of increasing social capital (Burke et al., 2010; Ellison et al., 2007; Steinfield et al., 2008) and self-esteem (Bargh et al., 2002; Helliwell and Putnam, 2004), diminishing loneliness and emotional distress that some people experience in 'true' interactions (Burke et al., 2010; Clayton et al., 2013; Sheldon, 2008b; Skues et al., 2012).

The literature shows that Facebook has a very significant influence on some of the most important evolutionary tasks typical of that age, such as the development of one's identity or the need to approach and be in contact with peers (Lenhart and Madden, 2007; Reich, 2010; Valkenburg et al., 2005; Valkenburg and Peter, 2008).

It should also be noted that by the end of the first month after the launch of the program, more than half of the college population, who witnessed the birth of Facebook, had registered on the site (Phillips, 2007). Since 2006, Facebook has been open to the public (Sheldon, 2008a; Urista et al., 2009) and has continued to record spectacular success. In terms of usability and access, he notes that through the Facebook platform it is possible to communicate with everyday friends, keep in touch with family and with friends who live far away, find old schoolmates or old childhood friends, meet new people or maintain contacts and relationships with people who share common interests (Buckman, 2005); you can send a message to another user containing a friend request (Kolek and Saunders, 2008).

Another peculiarity of Facebook is the flexibility and versatility of the platform that allows third parties to develop applications of a wide range of genres, such as games, surveys or quizzes that can be downloaded by other members of the network (Nash, 2011; Ries, 2010). This is configured as a real change of status highlighted by a series of public messages that appear on their bulletin board, within which photographs, music, video or links both by the user himself and his "friends" can also be uploaded (Grimmelmann, 2009). Moreover, private messages can be sent to any other user, a function similar to sending an email but without the need to know the recipient's email address (Golder et al., 2007; Pempek et al., 2009). At the same time, Facebook sends the user information about the activities of friends (Cheung et al., 2011; West et al., 2009). Having become an integral part of the daily lives of hundreds of millions of people, as well as a central and indispensable means of social interaction (Gosling et al., 2011), the attempt to monitor the positive and negative impacts that Facebook can have on people and society in general, as with other social networks, such as Twitter, Instagram, etc. can not leave us surprised.

Facebook is one of the most popular and famous sites in the world, especially among teenagers and young adults (Boyd, 2007, Valenzuela et al., 2009). In particular, the age range that is most associated with the use of Facebook is between 19 and 25 (Facebook, 2013b). According to numerous authors, Facebook is the main social networking site used by university students (Educause, 2006; Golder et al., 2007; Stutzman, 2006). In this regard, more than 90\% of college students in the United States have an account on Facebook (Ellison et al., 2007; Stutzman, 2006; Wiley and Sisson, 2006), while in England the percentage rises to 95\% (Madge et al., 2009).

The studies presented so far have shown how Facebook is a daily experience (especially for young people) (Pempek et al., 2009). In this regard, Pempek and colleagues (2009) found that the students reported spending about 30 minutes on Facebook every day. Overall, the results of the surveys that analyzed the percentage of time spent daily on the site ranged between 10 and 60 minutes (Christofides et al., 2009; Ellison et al., 2007; Joinson, 2008; Lampe et al., 2006; Muise et al., 2009; Orr et al., 2009; Ross et al., 2009; Valenzuela et al., 2009). More recent surveys have shown slightly higher daily times (Kalpidou et al., 2011; Panek et al., 2013). For example, the survey conducted by Junco (2012) documented a daily average of time spent on Facebook of just over 100 minutes, while Ryan and Xenos (2011) found that $17 \%$ of participants reported to spend up to 2 hours a day on Facebook and $19 \%$ even more than 2 hours. It is possible that the recent dissemination and availability of the internet connection on the mobile phone, which allows users to access the site at any time through the Facebook application, is the cause of this greater incidence of daily time spent on the site (Arestivo, 2013).

In association with the amount of time spent on Facebook, the age of the users may affect the use of Facebook. In particular, younger users tend to spend much more time on the site than older ones (Joinson, 2008; Kolek and Saunders, 2008; McAndrew and Jeong, 2012; Pempek et al., 2009; Valenzuela et al., 2009).

Another stream of literature has analyzed the motivation of the use of this platform. It should be noted, first of all, how the use of Facebook allows and facilitates interpersonal relationships (Ellison et al., 2007; Lenhart and Madden, 2007; Wiley and Sisson, 2006). Other reasons, although less relevant and frequent than the previous one, concern the possibility of using Facebook to meet new people in order to develop new friendships or a romantic relationship (Charnigo and Barnett-Ellis, 2007; Lenhart and Madden, 2007; Lewis and West, 2009); its use for entertainment and 
entertainment purposes, to kill time or to distract oneself in moments of boredom (Lampe et al., 2007; Pempek et al., 2009; Sheldon, 2008a).

In addition, other motivations for using Facebook emerge: as a means to seek emotional support (Ellison et al., 2006; Joinson, 2008), to search and share information (Kim et al., 2011; Lampe et al., 2006; Lin and Lu, 2011), or to express oneself and to introduce oneself, through changes in status and contents published on one's profile (Joinson, 2008; Pempek et al., 2009). The authors who deepened these aspects were motivated by some concerns about the potential risks that may be related to the disclosure of their information on a Social Network site, such as the violation of privacy, the possibility of identity theft, the vulnerability to possible offenders or pedophiles, or the use of data by third parties (Gross and Purchases, 2005).

Furthermore, a substantial range of studies has investigated the effects that Facebook can have on psychological well-being and on the interpersonal relationships of its users (Clerkin et al., 2013; Hayes et al, 2015; Jin, 2015; Hu et al., 2017). In this regard, some authors have advanced the hypothesis that such a phenomenon could produce a drift towards a new form of internet dependence, thus representing a powerful risk factor for the individual (Griffiths, 2000; Young, 2004) that it could gradually lead him/her away from the genuine face-to-face interactions typical of the "real world" (Sheldon et al., 2011). Nevertheless, although in general the impact that Social Networks can have on interpersonal relationships has been the subject of a long and articulated scientific debate (Nie, 2001;Baym et al., 2004; Caplan, 2007; Mazer et al., 2007;), most of the studies that have taken Facebook into account have documented how users report perceiving time passing on-line as an extension, rather than a substitution, of daily face-to-face interactions of the off-line context (Cheung et al., 2011; Kujath, 2011). The interaction created between users and social networks is considered to be a mediated interaction (Thompson 1998). In line with these studies, other authors have supported the possibility that this tool may have a positive impact on the individual, facilitating, for example, the connection between people and thus responding to some social needs of individuals (Ellison et al., 2007, Mathwick et al., 2008; Steinfield et al., 2008).

\subsection{Twitter}

The use of Twitter is based on four-key concepts generally shared by all its members, as Prunesti (2016) points out, namely:

- maximum openness of online conversations: the conversations that are generated are generally visible to all users;

- instantaneous communication: it is possible to condense in 140 characters a public message including text, hyperlinks and mentions of other Twitter users or it is possible to send a private message to a specific user;

- the principle of following: Twitter is an asynchronous social network, as it allows users to follow the flow of tweets generated by other users without these users necessarily being obliged to follow theirs;

- the possibility of aggregating tweets by keywords: conversations on Twitter are aggregated by topics thanks to the use of a specific corresponding hashtag. In Italy, the use of hashtags is used in a significant way to aggregate the discussions generated by television broadcasts.

Twitter, with its 330 million active users worldwide, of which 8 million represent Italian users (Global Digital Report, 2018), is one of the most used channels by Italian politicians. This social network connects anonymous users from all over the world, offering them the opportunity of a space in which to break and contextualize the news (Hermida, 2010) and this feature makes it one of a kind. Twitter users can follow people or organizations based on the topic or their specific interest (Jansen et al., 2009) also for this reason, our politicians are predisposed to use Twitter as a tool of connection between themselves and the citizens (Castells, 2013) but also as cross-talk between parliamentarians on hot topics with the possible generation of heated debates. However, a study by Velasquez (2012) suggests that politicians, journalists and officials are producers of information, while the non-traditional politician is considered a consumer of information. However, in regard to this study, it is necessary to consider the composition active and non-active Twitter users. There are many members on this social media, but about $90 \%$ of them limited their activity to observing and tweet very little compared to the $10 \%$, instead, who are considered very active (Bruns and Stieglitz, 2012).

The elements that characterize this particular social media are many, from the possibility of having a "digital track" (Freelon, 2014); through hyperlinks and retweets it is possible to analyze the activities of a user. These elements also allow us to know which topics a user is more interested in, as the user demonstrates their interest in a certain content (De Maeyer, 2013). It should also be noted that retweets represent a system of shared conversations, without the 
retweeter necessarily being a contributor of personal information (Boyd et al., 2010). Also, many retweets of the same post, give more visibility to the original issuer of the post (Ausserhofer and Maireder, 2013).

\subsection{Instagram}

Instagram is a particular social media based on sharing photos and videos online. Since its launch in 2010 to date there are 1 billion users worldwide, while in Italy it is used by 16 million Italians (Global Digital Report, 2018). The fact that it is easy to use is due to the technological supports it uses, in fact it is a social media that is based on the downloadable phone app, from which you can take pictures and videos directly, with the integrated possibility to edit images; in short allowing the user to be a professional photographer for a moment.

All photos and videos made on Instagram can easily be posted not only on your Instagram social profile but also simultaneously on other social networks like Facebook and Twitter. This is a very interesting feature for a social network. For the rest, the features are similar to those offered by Twitter. Ultimately, even in this social media there is a continuous flow of information that can be considered, as for all other social networks of this kind, a stream of social awareness (Naaman et al., 2010).

\section{Exploitative Communication: Focus on Interactions}

Thompson (1998) identifies the types of interaction that stand out from each other depending on whether or not they share the same space-time environment, namely: interaction face-to-face, quasi-mediated interaction, and mediated interaction. The most common interactions are face-to-face and quasi-mediated interaction, while mediated interaction is part of the characteristics of exploitative communications.

Face-to-face interaction is that between two individuals present in the same physical place and at the same time, that is, they share the same reference system. This allows for a dialogic interaction that allows those who are interacting to enrich their communication with non-verbal language made up of expressions, tones, gestures, etc.

The quasi-mediated interaction (Thompson, 1998) refers to those interactions where the contents of the message conveyed are produced for a set of undefined potential receivers. This is the case, for example, with books, newspapers and radio, which are instruments of mass communication that give rise to a new type of social interaction (Horton and Wohl, 1956). In this case, the flow of communication is almost completely unidirectional, that is from the source to the recipients, and for this reason it is called "quasi-interaction".

The aforementioned research by Charlene and Bernoff (2008) shows how the vast majority of users read online content, even if you do not actively participate with comments, references or shares. However, even if there is no active participation, these people are influenced by the content they find online.

The web site is the first step that an organization carries out within the network, in order to be present on the web. The site is the ideal place to synthesize and tell institutionally what the company is dealing with, the services it offers, its eventual location, and the modalities of the contract. Also, the site represents the "home" and the reference to which the corporate communication strategies are supported, by the various social networks, blogs and micro-blogging (i.e., explorational communication).

\section{Hypothesis}

In this study the definitions of Thompson (1998) were considered and a distinction was made between the analysis variables: exploitative and explorational communications, while making only a slight change in the author's original definition. Indeed, the only difference present is seen in that face-to-face interaction is considered to be an exploitative communication strategy, rather than an explorational communication strategy. This difference was intended with reference to the context of study, that is, with respect to politics and politicians, one thinks of the rallies or face-to-face meetings that a politician makes during the electoral campaign. During these meetings it is always the politician who holds the conversation and his interlocutor is more attentive to listening and is almost influenced by the very presence of the same.

Therefore, the research hypothesis is as follows:

H1: Explorational and exploitative forms of communications interact thereby influencing the effectiveness of communication for politicians?

\section{Method and Procedure}

We collected data about votes by section, number elected by section, average voters for the last legislature for each Italian party. Data were extracted from the Minister of Internal Affairs. In particular, three variables were considered: (1) votes by section, which refers to the number of votes the party received in that section, (2) elected by section, 
which indicates the number of parliamentarians elected for that party in that section, and (3) average voters, which indicates the average value of voters that any parliamentarians of any party obtained in each section, this a complex variable and this value is equal to the number of voters by section divided by the number elected by section.

Data about "Followers" on Facebook, "Likes" on Instagram, "Likes" on Facebook, Followers on Instagram, Facebook Profile and Followers of Twitter for the last legislature for each Italian party have been acquired from the social page of every parliamentarian. The Followers on Facebook variable indicates the number of followers that any parliamentarian has on Facebook. We have two variables for Instagram. The first variable, Likes, indicates the numbers of likes that every politician received for his post; the second variable is Followers on Instagram that measures the number of followers that each parliamentarian has on his Instagram Profile. With regard to Facebook, we considered a dummy variable; this variable is equal to 1 when the politician has a Facebook Profile, otherwise this value is equal to 0 . The last variable is the Followers on Twitter. This variable indicates the number of followers that each parliamentarian has on his Twitter Profile (Table 3).

Table 1. Illustrates sources of data

\begin{tabular}{|c|c|c|c|}
\hline Source of data & Data acquired & Time period & Area of study \\
\hline \multirow{3}{*}{ INTERIOR MINISTER } & Voters by section & \multirow{11}{*}{$\begin{array}{l}\text { Last legislature } \\
(2012-2017)\end{array}$} & \multirow{11}{*}{ Italy } \\
\hline & Elected by section & & \\
\hline & Average voters & & \\
\hline \multirow{8}{*}{ SOCIAL PAGE } & Follower on Facebook & & \\
\hline & Like on Instagram & & \\
\hline & Like Facebook & & \\
\hline & Follower on Instagram & & \\
\hline & Facebook Profile & & \\
\hline & Follower of Twitter & & \\
\hline & Insured Value $(1,000 €)$ & & \\
\hline & Total Premium $(1,000 €)$ & & \\
\hline
\end{tabular}

\section{Results and Discussion}

Five models were created and they are estimated for the most important Parties of the last legislature in which reliable data exist for votes by section, number elected by section, average voters, Followers on Facebook, Likes Instagram, Likes Facebook, Followers on Instagram, Facebook Profile and Followers on Twitter. We analyzed the cross section data for the last legislature through the OLS technique as it was the only time span for which all the variables were present. The OLS estimator chooses the regression coefficients so that the regression line estimated falls as close as possible to the observed data, where proximity is measured by the sum of the squares of errors that are committed in predicting $\mathrm{Y} \mathrm{X}$ data.

Five analyses were conducted to verify the robustness of empirical results. In this case, we have five independent variables for Average voter one for each principal party, for each model they were regressed on independent variables, i.e. Followers on Facebook (FollowF), Likes Instagram (Likeinsta), Likes Facebook (LikeFace), Followers on Instagram (FollowI), Facebook Profile (FaceP) and Followers of Twitter (FollowT).

$$
\begin{aligned}
\text { AverageVortesM5S }_{i, t} & =\alpha_{1}+\beta_{1} \text { Follow }_{i, t}+\beta_{2} \text { LikeInsta }_{i, t}+\beta_{3} \text { LikeFAce }_{i, t}+\beta_{4} \text { FollowI }_{i, t} \\
& +\beta_{5} \text { FaceP }_{i, t}+\beta_{6} \text { Follow }_{i, t}+\varepsilon_{1, t} \\
\text { AverageVortesLega }_{i, t} & =\alpha_{1}+\beta_{1} \text { Follow }_{i, t}+\beta_{2} \text { LikeInsta }_{i, t}+\beta_{3} \text { LikeFAce }_{i, t}+\beta_{4} \text { FollowI }_{i, t} \\
& +\beta_{5} \text { FaceP }_{i, t}+\beta_{6} \text { Follow }_{i, t}+\varepsilon_{1, t}
\end{aligned}
$$




$$
\begin{aligned}
\text { AverageVortesPD }_{i, t}= & \alpha_{1}+\beta_{1} \text { Follow }_{i, t}+\beta_{2} \text { LikeInsta }_{i, t}+\beta_{3} \text { LikeFAce }_{i, t}+\beta_{4} \text { FollowI }_{i, t} \\
& +\beta_{5} \text { FaceP }_{i, t}+\beta_{6} \text { Follow }_{i, t}+\varepsilon_{1, t} \\
\text { AverageVortesPDL }_{i, t}= & \alpha_{1}+\beta_{1} \text { Follow }_{i, t}+\beta_{2} \text { LikeInsta }_{i, t}+\beta_{3} \text { LikeFAce }_{i, t}+\beta_{4} \text { FollowI }_{i, t} \\
& +\beta_{5} \text { FaceP }_{i, t}+\beta_{6} \text { Follow }_{i, t}+\varepsilon_{1, t} \\
\text { AverageVortesSEL }_{i, t} & =\alpha_{1}+\beta_{1} \text { Follow }_{i, t}+\beta_{2} \text { LikeInsta }_{i, t}+\beta_{3} \text { LikeFAce }_{i, t}+\beta_{4} \text { FollowI }_{i, t} \\
& +\beta_{5} \text { FaceP }_{i, t}+\beta_{6} \text { Follow }_{i, t}+\varepsilon_{1, t}
\end{aligned}
$$

The previous table shows five different models. Each model shows the impact of the variables analyzed on the dependent variable AverageVoters for every party. The model (1), present in Table 2, demonstrates the impact of independent variables on the dependent variable AverageVot for the Movimento 5 Stelle party.

Table 2. Summary statistics (movimento 5 stelle)

\begin{tabular}{lllll}
\hline Variables & Mean & Standard deviation & Minimum & Maximum \\
\hline FollowF & $3.259,21$ & $\mathbf{1 , 4 4}$ & 0 & 172.201 \\
\hline LikeInsta & 991,79 & $212.359,36$ & 0 & 27.167 \\
\hline LikeFace & $57.510,33$ & 0,41 & 0 & 2.112 .431 \\
\hline FollowI & 18.10 & 0,29 & 5.50 & 457.010 \\
\hline FaceP & 0,79 & 35480,20 & 0 & 1 \\
\hline FollowT & $6.856,22$ & $190.596,87$ & 0 & 545.944 \\
\hline
\end{tabular}

The second model (2), present in Table 3, shows the effect of independent variables on dependent variable AverageVot for the Lega party.

Table 3. Summary statistics (lega)

\begin{tabular}{lllll}
\hline Variables & Mean & Standard deviation & Minimum & Maximum \\
\hline FollowF & $7.207,11$ & 36326,40 & 0 & 243.956 \\
\hline LikeInsta & $1.361,867$ & 2441,07 & 0 & 12.161 \\
\hline LikeFace & 84743,422 & 480701,1 & 0 & 32.34 .355 \\
\hline FollowI & 22.500 & 133993,16 & 0 & 901.044 \\
\hline FaceP & 0,84 & 0,37 & 0 & 1 \\
\hline FollowT & $20.035,97$ & 127133,09 & 0 & 853.711
\end{tabular}

The third model (3), present in Table 4, evaluated the impacts of the independent variables on the dependent variable AverageVot for the PD party. 
Table 4. Summary statistics (partito democratico)

\begin{tabular}{lllll}
\hline Variables & Mean & Standard deviation & Minimum & Maximum \\
\hline FollowF & $1.107,68$ & $3.357,44$ & 0 & 39.732 \\
\hline LikeInsta & $1.514,26$ & 3791,88 & 0 & 43.658 \\
\hline LikeFace & 9220,783 & 24560,89 & 0 & 195.223 \\
\hline FollowI & $18.956,36$ & $77.634,15$ & 0 & 635.660 \\
\hline FaceP & 0,71 & 0,45 & 0 & 1 \\
\hline FollowT & 817,67 & $3.680,76$ & 0 & 54.593 \\
\hline
\end{tabular}

The model (4), that is present in Table 5, shows the impact of the independent variables on the dependent variable for the PDL party.

Table 5. Summary statistics (Popolo Della Libertà)

\begin{tabular}{lllll}
\hline Variables & Mean & Standard deviation & Minimum & Maximum \\
\hline FollowF & 715,65 & $3.568,95$ & 0 & 41.215 \\
\hline LikeFace & $13.721,013$ & $78.783,45$ & 0 & 1.059 .973 \\
\hline LikeInsta & 875,48 & $3.790,98$ & 0 & 38.044 \\
\hline FollowI & $13.757,45$ & $53.054,07$ & 0 & 562.847 \\
\hline FaceP & 0,60 & 0,49 & 0 & 1 \\
\hline FollowT & $1.518,14$ & 11341,46 & 0 & 154.000 \\
\hline
\end{tabular}

The last model (5), that is present in Table 6, underlines the impact of the independent variables on our dependent variable for the SEL party.

Table 6. Summary statistics (Sinistra Ecologia e Libertà)

\begin{tabular}{lllll}
\hline Variables & Mean & Standard deviation & Minimum & Maximum \\
\hline FollowF & 963,62 & $2.639,93$ & 0 & 16.923 \\
\hline LikeInsta & 845,31 & $5.025,57$ & 0 & 36.950 \\
\hline LikeFace & $9.119,61$ & $39.835,80$ & 0 & 291.143 \\
\hline FollowI & $19.544,33$ & $116.578,78$ & 0 & 859.353 \\
\hline FaceP & 0,66 & 0,47 & 0 & 1 \\
\hline FollowT & 548,46 & $2.751,10$ & 0 & 20.200 \\
\hline
\end{tabular}

The columns labeled (1), (2), (3), (4) and (5) included in Table 7, report the results of the five separate pooled OLS regressions. The values in the table are the coefficients, standard errors (in parentheses), their p-values, and summary statistics, as indicated by the description in each row.

Table 7 illustrates the results of the five separate pooled OLS regressions. 
Table 7. Results

\begin{tabular}{|c|c|c|c|c|c|c|}
\hline \multirow[b]{2}{*}{ Constant } & \multicolumn{2}{|c|}{ AverageVot (M5S) } & \multicolumn{2}{|c|}{ AverageVot (Lega) (2) } & \multicolumn{2}{|c|}{ AverageVot (PD) (3) } \\
\hline & $97917,1 * * *$ & 7849,08 & $76359,1 * * *$ & 6760,20 & $49393,2 * * *$ & 3682,56 \\
\hline FollowF & $-0,460609 * *$ & 0,232218 & $-0,482091$ & 0,874739 & 0,141158 & 0,428875 \\
\hline LikeInsta & $0,155729 * *$ & 0,0741934 & 0,136353 & 0,129758 & 0,0226256 & 0,127114 \\
\hline LikeFace & $-1,22454 * * *$ & 0,444977 & $2,92039 * *$ & 1,23970 & $-0,502415 * * *$ & 0,187177 \\
\hline FollowI & $-0,514916^{*}$ & 0,274785 & $-2,57547 * * *$ & 0,962757 & $-0,0446141$ & 0,0399593 \\
\hline FaceP & 3560,11 & 8001,06 & $-7383,95$ & 7453,74 & $-8859,05 * *$ & 4127,13 \\
\hline Follow $T$ & $-0,233445^{* *}$ & 0,123920 & 1,59091 & 1,32695 & $1,28074^{*}$ & 0,770950 \\
\hline \multicolumn{7}{|c|}{ Summary Statistics } \\
\hline SER & 35099,38 & & 16326,40 & & 30704,75 & \\
\hline$R^{2}$ & 0,062706 & & 0,255995 & & 0,041292 & \\
\hline
\end{tabular}

\begin{tabular}{llllc}
\hline & AverageVot (PDL) & (4) & AverageVot (SEL) & (5) \\
\hline Constant & $67803,6^{* * *}$ & 2721,30 & $20094,8 * * *$ & 2823,14 \\
\hline FollowF & $-0,613411^{*}$ & 0,323810 & $-1,59965$ & 1,28579 \\
\hline LikeInsta & 0,0403648 & 0,0788972 & 1,04811 & 0,737290 \\
\hline LikeFace & $0,554003 *$ & 0,294101 & $-1,31215$ & 0,969497 \\
\hline FollowI & $0,0526912^{*}$ & 0,0282560 & $-0,387568 *$ & 0,201049 \\
\hline FaceP & $8926,25 * *$ & 4290,93 & $16806,7 * *$ & 7034,63 \\
\hline FollowT & $-2,67171^{* *}$ & 1,03518 & $-2,84086$ & 4,24440 \\
\hline Summary Statistics & & & 20295,59 & 0,132797 \\
\hline SER & 28510,62 & & \\
\hline$R^{2}$ & 0,049694 & & \\
\hline
\end{tabular}

The first column of labeled regression results (1) in the table consider a linear relation between the dependent variable AverageVot (M5S). Results of the first regression analysis show how all the variables taken in consideration are significant, which is expressed by the p-value that for each variable is equal to $(<0.001,0.005,0.01)$.

The analysis shows how the politicians of the 5-star movement are the most active on social channels, in the model (1) the variables are significant, but such an impact significantly changes according to the type of social network. The independent variable has a positive relationship with the variable Likes on Instagram, but has negative relationships with other social pages, such as Facebook and Twitter. In the second model we have only a single significant independent variable, this variable is Likes on Facebook and this variable has a positive relation with our dependent variable. In model (3) the analysis shows a close negative relation between the use of communication and the Averagevot for the PD party. The last two models describe the relationship between our independent variables and our dependent variable for the PDL and SEL party. For the first party the results indicate that there is a positive significant relation between the use of the social Facebook and our dependent variable; instead, the last model shows that for this party the use of Facebook is the most important because this is the only significant variable.

Focusing on the summary statistics of regression, it is possible to notice the value assumed by R2, quantifying the extent to which the explanatory variables explain the variation on the dependent variable. 


\section{Supplementary Analysis}

\subsection{Methodology and Procedure}

In order to test our research hypothesis, in this section the possible interaction between exploitative and explorational communication and how it impacts the effectiveness of communication was verified.

This analysis aims at examining the relationship between traditional forms of communication used by politicians (here intended as the use of a personal website) and the use of social network (here measured in terms of the number of posts on Twitter) in influencing the tendency to be followed on social networks.

This study aims to demonstrate that the choice of politicians in adopting both exploitative communication and explorational communication is more effective and efficient than choosing to adopt a single strategy.

In order to achieve this objective, data concerning traditional channels - in particular the use of institutional websites and personal websites - and data relating to social media in particular, were collected for each individual parliamentarian (deputies and senators). This data collection was carried out over a period of six months.

\subsection{Results}

A moderation analysis (Model 1) was conducted using the SPSS PROCESS Macro by Hayes (2013) can be seen in Figure 1, in which followers on Twitter served as the dependent variable.

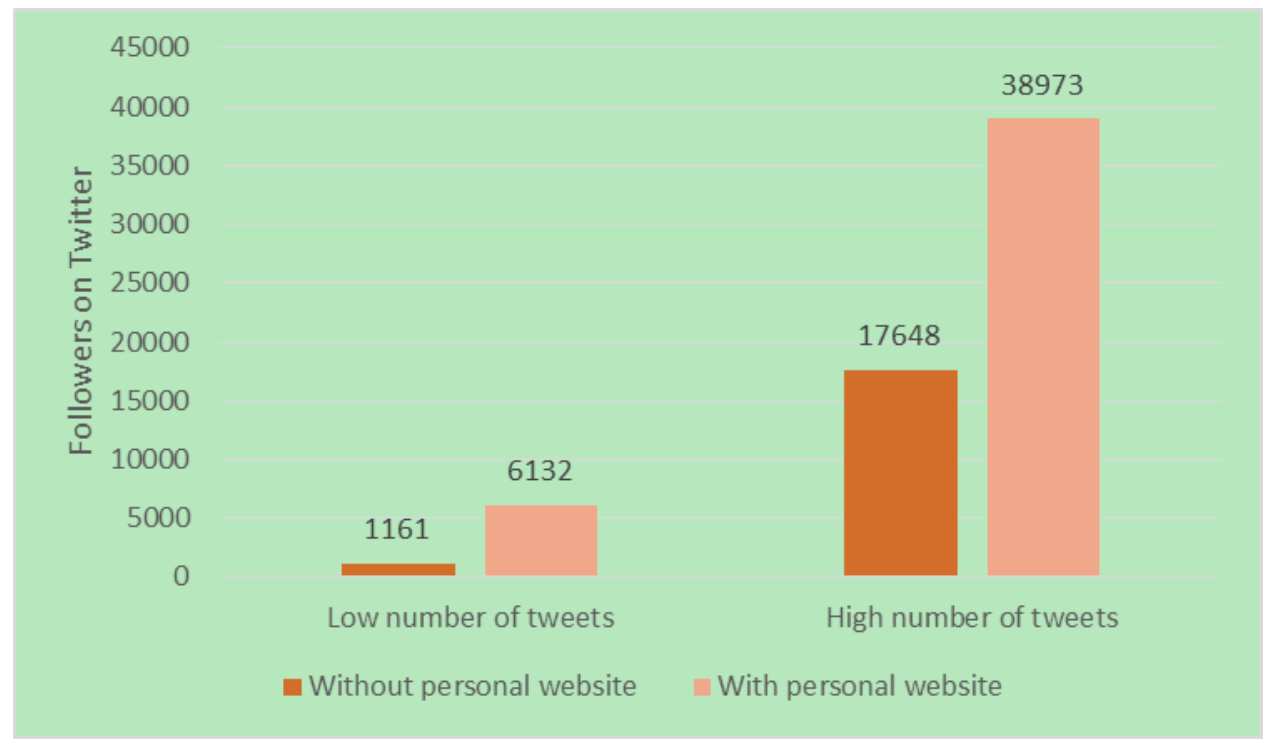

Figura 1. Followers on Twitter as a function of the presence of personal website, the number of posts and their interaction

This was expressed as a function of the presence of personal website (measured as a binary variable coded as -1 when politicians do not have a personal website and 1 when they have a personal website), the number of tweets (measured as a continuous variable and mean-centered), and their interaction.

The results revealed a main effect of the presence of a personal website on the dependent variable that was positive significant $(b=6574.05, t(1004)=2.75, \mathrm{p}=0.01)$, indicating that politicians having a personal website have a greater probability to be followed on Twitter. There was also a positive significant effect of the number of posts on Twitter on the number of followers $(b=1.4, t(1004)=4.37, p=0.00)$. The interaction effect between the presence of the personal website and number of posts on Twitter was, instead, non-significant $(b=0.46, t(1004)=1.45, p=0.15)$. The effect of the participation in working commissions was also controlled and found to have a negative significant effect $(b=-3421.01, t(1004)=-2.86, p=0.00)$, suggesting that politician's effort to produce laws has detrimental consequences in terms of followers on social networks.

Although the interaction effect was non-significant, the conditional effects revealed that, in absence of a personal website, the effect of the number of posts on Twitter does not significantly affect the number of followers $(b=0.94$, 
$\mathrm{p}=0.10$ ); whereas, in the presence of a personal website, the effect of the number of posts on Twitter significantly affects the number of followers $(b=1.86, p=0.00)$, thus supporting the research hypothesis. Such a result suggests that using a personal website increases the efficacy of the posts published on Twitter, thus providing evidence for the "ambidexterity effect".

\section{Discussions and Conclusions}

This work aimed at investigating how politicians use various sources of communication (explorational and exploitative) and the impact of these two forms of communication on the effectiveness of communication. So the attention fell on Facebook with its 34 million subscribers, a figure that makes it the most widespread and used social media in our national context. Subsequently, the study focused on Twitter with its 8 million users, which grow day by day and on Instagram with 16 million subscribers, data that always refers to the Italian territory (Global Digital Report, 2018). These three social media represent a model of reference especially for the younger generations, which has inspired the advent of new forms of relationships.

It was amply highlighted how Facebook has had and continues to have a huge impact on the social life of hundreds of millions of people (Bargh and McKenna, 2004; Zickuhr, 2010) and how a large number of scholars have dedicated themselves to the investigation of this phenomenon, analyzing various aspects related to the use of this Social Network.

There are numerous social and psychological advantages related to the use of these social media. Among these, in particular the possibility of increasing the share capital was highlighted (Burke et al., 2010; Ellison et al., 2007; Gonzales and Hancock, 2011; Steinfield et al., 2008; Tazghini and Siedlecki, 2013).

The most evident risks of this communication phenomenon are linked to a possible dependence on them, but also to the diffusion of personal data, to the exposition of confidential information, to the possibility of compromising one's image and, again, to the risk of being the object of the phenomena of cyber bullying (Gross and Purchases, 2005; Kwan, and Skoric, 2013; Miller and Hufstedler, 2009).

Besides the negative effects, literature shows that Facebook has positive effects on the aim of facilitating communication and keeping in contact with friends. In fact, Facebook as Twitter would represent an effective way to achieve this goal by facilitating the sense of belonging, communication and contact with friends (Yu et al., 2010).

Factors related to privacy, rather than the sphere of image ownership, must also be taken into due consideration. In fact, all the material shared on Facebook, including images, once placed on the network, both from a legal point of view and from a practical point of view, no longer belong only to the user, but can spread without the author being able to stop its dissemination or its elimination (Brown et al., 2009). Nevertheless, the planetary users of Facebook users do not seem to be particularly persuaded by the idea of putting a stop to the sharing of personal content on this social network.

The exploitative communication part of the study focused on identifying the use of each parliamentarian and the parties of institutional websites, such as for example the websites of the Senate and the Chamber and the websites of the parties. In this analysis, the presence and use of personal websites for each politician were considered as traditional channels, while the other traditional means of communication, such as for example rallies, leafleting etc., were taken for granted. This because, during the data search it was highlighted that all politicians used traditional channels in their campaign path, but it was not possible to collect data more precisely. As a consequence, each politician analyzed has the same way of using traditional channels, but not the same way of using the three social channels analyzed.

The results of the first step of analysis show that there is a correlation between the use of social networks, and political performance but it is not the same for every single party. The various linear regressions allow us to affirm that not all political parties have the same feedback on the different channels of communication. A possible explanation for this can be given by the different age groups that make up the passive electorate of every single passive. The only party where the Instagram channel has shown a significant positive relationship with this result is Movimento 5 Stelle, this likely stems from the fact that the electorate of Movimento 5 Stelle is predominantly composed of young people; while for parties that have existed for a long time whose electorate is mainly composed of people with a higher age group, there is a positive correlation with the use of the social network Facebook. These results demonstrate how the phenomenon called communication ambidexterity exists within the Italian political landscape. Even if this analysis must be deepened by further scientific research to improve two aspects: The first aspect concerns the dependent variable. In order to improve the analysis, it should be more precise. The second 
aspect is the temporal misalignment between the communicative variables and the independent variable, as these variable refer to a time span that goes from 2012 to today, but there are no data for all years.

Subsequently, after the first phase of analysis, a second phase was carried out, in which all the data concerning the Twitter social network were analyzed - as far as explorational communication is concerned - and the presence and use of institutional and personal sites for every single member of the XVII legislature - regarding the exploitative communication.

The results of this second step of analysis show that using a personal website increases the efficacy of the posts published on Twitter, thus providing evidence for the "ambidexterity effect". Consequently, the use of both strategies, exploitative and explorational communications - are more effective than the choice of using only one of these, confirming the starting hypothesis.

This study has found important and significant results compared to the use of social media by Italian politicians. However, it has many potentialities to explore. For example, the individual political profiles could be analyzed in more detail year by year, in order to see the progress of their exploitative communication. In addition, a cross-comparison between the activities and the active discussions on their social profiles on sustainability issues could be made and compared with the acts that each parliamentary approved or presented in the Chamber of Deputies rather than the oppositions to completed bills in the Senate. Or again, it would be interesting to evaluate how effectively a politician is not only active on social networks but how effectively in real life (off-line) and how often he is active in the parliamentary context, evaluating their presence or missions. to For example they may be good with discussions on social media, but maybe in Parliament they are considered ghosts. Finally, it would be interesting to study how and if their activities in Parliament and online continue in today's legislature. In short, there are many ideas to expand this research work and the results would be useful to politicians and citizens, as well as a giving a broader vision to all organizations operating in the Italian market.

\section{References}

Abruzzese, A., \& Mancini, P. (2007). Sociologie della comunicazione. Laterza \& Figli, Roma-Bari.

Arestivo, G. (2013). Facebook è l'applicazione preferita per gli smartphone nel 2013.

Arnesano, G. (2007). Viral marketing e altre strategie di comunicazione innovativa. Frano Angeli, Milano.

Ausserhofer, J., \& Maireder, A. (2013). National politics on Twitter: Structures and topics of a networked public sphere. Information, Communication \& Society, 16(3), 291-314. https://doi.org/10.1080/1369118X.2012.756050

Backstrom, L. (2011). Anatomy of Facebook. Palo Alto, CA: Facebook.

Backstrom, L., Boldi, P., Rosa, M., Ugander, J., \& Vigna, S. (2011). Four degrees of separation. Retrieved from http://arxiv.org/abs/1111.4570

Baltaretu, C. M., \& Balaban, D. C. (2010). Motivation in using social network sites by Romanian students. A qualitative approach. Journal of Media Research, 1, 67-74.

Bargh, J. A., \& McKenna, K. Y. A. (2004). The internet and social life. Annual Review of Psychology, 55, 573-590. https://doi.org/10.1146/annurev.psych.55.090902.141922

Bargh, J. A., McKenna, K. Y., \& Fitzsimons, G. M. (2002). Can you see the real me? Activation and expression of the "true self" on the Internet. Journal of Social Issues, 58, 33-48. https://doi.org/10.1111/1540-4560.00247

Baumeister, R. F., \& Leary, M. R. (1995). The need to belong: Desire for interpersonal attachments as a fundamental human motivation. Psychological Bulletin, 117, 497-529. https://doi.org/10.1037/0033-2909.117.3.497

Baym, N. K., Zhang, Y. B., \& Lin, M. (2004). Social interactions across media: Interpersonal communication on the internet, telephone and face-to-face. New Media \& Society, 6, 299-318. https://doi.org/10.1177/1461444804041438

Bayton, J. A. (1985). Motivation, cognition, learning. Basic factors in consumer behaviour. Journal of Marketing, 1 , 282. https://doi.org/10.2307/1247119

Bergman, S. M., Fearrington, M. E., Davenport, S. W., \& Bergman, J. Z. (2011). Millennials, narcissism, and social networking: What narcissists do on social networking sites and why. Personality and Individual Differences, 50, 706-711. https://doi.org/10.1016/j.paid.2010.12.022 
Bosch, T. E. (2009). Using online social networking for teaching and learning: Facebook use at the university of cape town. South African Journal for Communication Theory and Research, 35(2), 185-200. https://doi.org/10.1080/02500160903250648

Boyd, D., Golder, S., \& Lotan, G. (2010). Tweet, tweet, retweet: Conversational aspects of retweeting on twitter. In 2010 43rd Hawaii international conference on system sciences (HICSS) (pp. 1-10). New York: IEEE. https://doi.org/10.1109/HICSS.2010.412

Boyd, D. M. (2007). Why youth (heart) social network sites: The role of networked publics in teenage social life. In D. Buckingham (Ed.), Youth, identity, and digital media volume (pp. 119-142). Cambridge, MA: MIT Press.

Boyd, D. M., \& Ellison, N. B. (2007). Social network sites: Definition, history, and scholarship. Journal of $\begin{array}{llll}\text { Computer-Mediated } & \text { Communication, } & \text { Retrieved from }\end{array}$ http://jcmc.indiana.edu/vol13/issue1/boyd.ellison.html

Boyd, D. M., \& Hargittai, E. (2010). Facebook privacy settings: Who cares?. First Monday, 5, 8. https://doi.org/10.5210/fm.v15i8.3086

Brown, J. D., Keller, S., \& Stern, S. (2009). Sex, Sexuality, Sexting, and SexEd: Adolescents and the Media. Prevention Researcher, 16(4), 12-16. https://doi.org/10.1037/e630642009-005

Brown, J. J. (2008). From Friday to Sunday: The hacker ethic and shifting notions of labour, leisure and intellectual property. Leisure Studies, 27, 395-409. https://doi.org/10.1080/02614360802334922

Bruns, A., \& Stieglitz, S. (2012). Quantitative approaches to comparing communication patterns on Twitter. Journal of Technology in Human Services, 30(3-4), 160-185. https://doi.org/10.1080/15228835.2012.744249

Buckman, R. (2005). Too much information? Colleges fear student postings on popular facebook site could pose security risks. The Wall Street Journal, B1.

Burke, D. M., Marlow, C., \& Lento, T. (2010). Social network activity and social wellbeing. Postgraduate Medical Journal, 85, 455-459.

Burns, A. (2009). From prosumer to produser: understanding user-led content creation. Trasforming audiences.

Cain, J. (2008). Online Social Networking Issues Within Academia and Pharmacy Education. American Journal of Pharmaceutical Education, 72(1). https://doi.org/10.5688/aj720110

Caplan, S. E. (2007). Relations among loneliness, social anxiety, and problematic internet use. CyberPsychology \& Behavior, 10, 234-242. https://doi.org/10.1089/cpb.2006.9963

Castells, M. (2013). Communication Power. Oxford: Oxford University Press.

Charlene, L., \& Bernoff, J. (2008). Groundsewell: winning in a world transformed by social technologies. Harvard Business Press, Boston.

Charnigo, L., \& Barnett-Ellis, P. (2007). Checking out Facebook.com: The impact of a digital trend on academic libraries. Information Technology and Libraries, 26, 23-34. https://doi.org/10.6017/ital.v26i1.3286

Chen, B., \& Marcus, J. (2012). Students' self-presentation on Facebook: An examination of personality and self-contrual factors. Computers in Human Behavior, 28, 2091-2099. https://doi.org/10.1016/j.chb.2012.06.013

Cheung, C. M. K., Chiu, P. Y., \& Lee, M. K. O. (2011). Online social networks: Why do students use facebook?. Computers in Human Behavior, 27, 1337-1343. https://doi.org/10.1016/j.chb.2010.07.028

Chieffi, D., Dani, C., \& Renzi, M. (2013). Working on web. Franco Angeli, Milano.

Christofides, E., Muise, A., \& Desmarais, S. (2009). Information disclosure and control on Facebook: Are they two sides of the same coin or two different processes?. CyberPsychology \& Behavior, 12(3), 341-345. https://doi.org/10.1089/cpb.2008.0226

Clayton, R. B., Osborne, R. E., Miller, B. K., \& Oberle, C. D. (2013). Loneliness, anxiousness, and substance use as predictors of Facebook use. Computers in Human Behavior, 29, 687-693. https://doi.org/10.1016/j.chb.2012.12.002

Clerkin, E. M., Smith, A. R., \& Hames, J. L. (2013). The interpersonal effects of Facebook reassurance seeking. Journal of Affective Disorders, 151(2), 525-530. https://doi.org/10.1016/j.jad.2013.06.038

Collesei, U. (2008). Marketing non convenzionale: nuovo marketing?. In Micro \& Macro Marketing (vol.3, pp. 459-464). 
Constantinides, E. (2004). Influencing the online cosumer's behaviour: The web experience. Journal of Internet Research, 14(2), 111-126. https://doi.org/10.1108/10662240410530835

Conti, L. (2010). Comunicare con Twittwer: ccreare relazioni, informarsi, lavorare, Hopeli. Milano.

Cosenza, V. (2012). Social media Roi, Apogeo. Milano.

Cova, B., Giordano, A., \& Pallera, M. (2007). Marketing non convenzionale, Edizioni il Sole 24 Ore. Milano.

De Maeyer, J. (2013). Towards a hyperlinked society: A critical review of link studies. New Media \& Society, 15(5), 737-751. https://doi.org/10.1177/1461444812462851

DeWall, C. N., Buffardi, L. E., Bonser, I., \& Campbell, W. K. (2011). Narcissism and implicit attention seeking: Evidence from linguistic analyses of social networking and online presentation. Personality and Individual Differences, 51, I57-162. https://doi.org/10.1016/j.paid.2011.03.011

Educause. (2006). 7 Things you should know about facebook. Educause Learning Initiative. Retrieved from http://net.educause.edu/ir/library/pdf/ELI7017.pdf

Ellison, N., Steinfield, C., \& Lampe, C. (2006). Spatially bounded online social networks and social capital: The role of Facebook. Proceedings of the Annual Conference of the International Communication Association, 36, 1-37.

Ellison, N., Steinfield, C., \& Lampe, C. (2007). The benefits of Facebook "friends": Social capital and college students' use of online social network sites. Journal of Computer-Mediated Communication, 12, 1143-1168. https://doi.org/10.1111/j.1083-6101.2007.00367.x

Facebook. (2011b). Using Facebook.

Facebook and Twitter. (n.d.). Computers in Human Behavior, 29, 2004-2012.

Facebook usage. (n.d.). Computers in Human Behavior, 27, 1658-1114.

Facebook. (2012). Statistics of Facebook. Palo Alto, CA: Facebook. Retrieved from http://newsroom.fb.com/content/default. aspx?NewsAreaId=22

Facebook. (2013b). Statistiche di Facebook. Retrieved from http://it.socialtimes.me/stat

Freelon, D. (2014). On the interpretation of digital trace data in communication and social computing research. Journal of Broadcasting \& Electronic Media, 58(1), 59-75. https://doi.org/10.1080/08838151.2013.875018

Garagnani, A. G. (1987). Il destino dell'uomo nella società post-industriale. Laterza e figli, Bari.

Global Digital Report. (2018). We are social and Hootsuite.

Goffman, E. (1986). La vita quotidiana come rappresentazione. Il Mulino, Bologna

Golder, S. A., Wilkinson, D., \& Huberman, B. A. (2007). Rhythms of social interaction: Messaging within a massive online network. In C. Steinfeld, B. T. Pentland, M. Ackerman, \& N. Contractor (Eds.), Communities and technologies 2007: Proceedings of the third communities and technologies conference (pp. 41-66). London: Springer-Verlag Limited. https://doi.org/10.1007/978-1-84628-905-7_3

Gonzales, A. L., \& Hancock, J. T. (2011). Mirror, mirror on my Facebook wall: Effects of exposure to Facebook on Self-Esteem. Cyberpsychology, Behavior, and Social Networking, 14, 79-83. https://doi.org/10.1089/cyber.2009.0411

Gosling, S. D., Augustine, A. A., Vazire, S., Holtzman, N., \& Gaddis, S. (2011). Manifestations of personality in online Social Networks: Self-reported Facebook-related behaviors and observable profile information. https://doi.org/10.1089/cyber.2010.0087

Griffiths, M. (2000). Does Internet and computer addiction exist? Some case study evidence. CyberPsychology and Behavior, 3, 211-218. https://doi.org/10.1089/109493100316067

Grimmelmann, J. (2009). Saving Facebook. Iowa Law Review, 94, 1137-1206.

Gross, R., \& Acquisti, A. (2005). Information revelation and privacy in online social networks. In S. D. C. di Vimercati, \& R. Dingledine (Eds.), Proceedings of the 2005 ACM workshop on Privacy in the electronic society (pp. 71-80). New York: ACM. https://doi.org/10.1145/1102199.1102214

Hallahan, K. (2000). Enhacing motivation, ability and opportunity to process public relations messages. Public Relations Review, 26(4), 463-480. https://doi.org/10.1016/S0363-8111(00)00059-X 
Hayes, M., van Stolk-Cooke, K., \& Muench, F. (2015). Understanding Facebook use and the psychological affects of use across generations. Computers in Human Behavior, 49, 507-511. https://doi.org/10.1016/j.chb.2015.03.040

Helliwell, J. F. K., \& Putnam, R. D. K. (2004). The social context of well-being. Philosophical Transactions of the Royal Society B. Biological Sciences, 359, 1435-1446. https://doi.org/10.1098/rstb.2004.1522

Hermida, A. (2010). Twittering the news: The emergence of ambient journalism. Journalism Practice, 4(3), 297-308. https://doi.org/10.1080/17512781003640703

Horizons. (2009). Indiana University, 52, 357-365. https://doi.org/10.1016/j.bushor.2009.03.002

Horton, D., \& Wohl, R. R. (1956). Mass communication and Para-Social Interaction: Observations on Intimacy at a Distance. Psychiatry, 19, 215-229. https://doi.org/10.1080/00332747.1956.11023049

Hu, X., Kim, A., Siwek, N., \& Wilder, D. (2017). The Facebook paradox: Effects of Facebooking on individuals' social relationships and psychological well-being. Frontiers in Psychology, 8, 87. https://doi.org/10.3389/fpsyg.2017.00087

Jansen, B. J., Zhang, M., \& Sobel, K. (2009). Twitter power: Tweets as electronic word of mouth. Journal of the American Society for Information Science and Technology, 60(11), 2169-2188. https://doi.org/10.1002/asi.21149

Jenkins, H. (2007). Cultura convergente. Maggioli Editore.

Jin, C. H. (2015). The role of Facebook users' self-systems in generating social relationships and social capital effects. New Media \& Society, 17(4), 501-519. https://doi.org/10.1177/1461444813506977

Joinson, A. N. (2008). Looking at, looking up or keeping up with people? Motives and use of Facebook. In Proceedings of the 26th Annual SIGCHI Conference on Human Factors in Computing Systems (pp. 1027-1036). New York, NY: ACM. https://doi.org/10.1145/1357054.1357213

Joseph, B. W., \& Kyle, P. D. (2001). The Impacts of Emoticons on Message Interpretation. Computer-Mediated Communication, Social Science Computer Review, 19, 324-347. https://doi.org/10.1177/089443930101900307

Junco, R. (2012). The relationship between frequency of Facebook use, participation in Facebook activities, and student engagement. Computers \& Education, 58(1), 162-171. https://doi.org/10.1016/j.compedu.2011.08.004

Kalpidou, M., Costin, D., \& Morris, J. (2011). The relationship between Facebook and the well-being of undergraduate college students. CyberPsychology, Behavior, and Social Networking, 14(4), 183-189. https://doi.org/10.1089/cyber.2010.0061

Karaiskos, D., Tzavellas, E., Balta, G., \& Paparrigopoulos, T. (2010). Social network addiction: a new clinical disorder?. European Psychiatry Volume, 25(1), 855. https://doi.org/10.1016/S0924-9338(10)70846-4

Kim, J., \& Lee, J. E. (2011). The Facebook paths to happiness: Effects of the number of Facebook friends and self-presentation on subjective well-being. Cyberpsychology, Behavior and Social Networking, 6, 359-364. https://doi.org/10.1089/cyber.2010.0374

Kim, Y., Sohn, D., \& Choi, S. (2011). Cultural difference in motivations for using social network sites: A comparative study of American and Korean college students. Computers in Human Behavior, 27(1), 365-372. https://doi.org/10.1016/j.chb.2010.08.015

Kolek, E. A., \& Saunders, D. (2008). Online disclosure: An empirical examination of undergraduate facebook profiles. NASPA Journal, 45(1), 1-25. https://doi.org/10.2202/0027-6014.1905

Kujath, C. L. (2011). Facebook and MySpace: Complement or substitute for face-toface interaction?. CyberPsychology, Behavior, and Social Networking, 14(1/2), 75-78. https://doi.org/10.1089/cyber.2009.0311

Kwan, G. C. E., \& Skoric, M. M. (2013). Facebook bullying: An extension of battles in school. Computers in Human Behavior, 29(1), 16-25. https://doi.org/10.1016/j.chb.2012.07.014

Lampe, C., Ellison, N., \& Steinfield, C. (2006). A Face (book) in the crowd: Social searching vs. social browsing. Paper presented at the Conference on computer supported cooperative work, New York. https://doi.org/10.1145/1180875.1180901

Lampe, C., Ellison, N., \& Steinfield, C. (2007). A familiar face (book): Profile elements as signals in an online social network. In Proceedings of the 26th annual SIGCHI conference on Human Factors in computing systems (pp. 435-444). New York: ACM. https://doi.org/10.1145/1240624.1240695 
Lenhart, A., \& Madden, M. (2007). Teens, privacy \& online social networks: How teens manage their online identities and personal information in the age of MySpace.Washington, DC: Pew Internet \& American Life Project.

Lenhart, A., Purcell, K., Smith, A., \& Zickuhr, K. (2010). Social Media \& Mobile Internet Use among Teens and Young Adults. Millennials. Pew internet \& American life project.

Lewis, J., \& West, A. (2009). 'Friending': London-based undergraduates' experience of facebook. New Media \& Society, 11(7), 1209-1229. https://doi.org/10.1177/1461444809342058

Lin, K., \& Lu, H. (2011). Why people use social networking sites: An empirical study integrating network externalities and motivation theory. Computers in Human Behavior, 27(3), 1152-1161. https://doi.org/10.1016/j.chb.2010.12.009

Lyotard, J. F. (2002). La condizione postmoderna; Feltrinelli. Milano.

Madge, C., Meek, J., Wellens, J., \& Hooley, T. (2009). Facebook, social integration and informal learning at university: 'It is more for socialising and talking to friends about work than for actually doing work'. Learning, Media \& Technology, 34(2), 141-155. https://doi.org/10.1080/17439880902923606

Mangold, W. G., \& Faulds, D. J. (2009). Social media: the new hybrid element of the promotion mix. Business. https://doi.org/10.1016/j.bushor.2009.03.002

Mathwick, C., Wiertz, C., \& De Ruyter, K. (2008). Social capital production in a virtual P3 community. Journal of Consumer Research, 34, 832-849. https://doi.org/10.1086/523291

Mazer, J. P., Murphy, R. E., \& Simonds, C. J. (2007). I'll see you on "Facebook": The effects of computer mediated teacher self-disclosure on student motivation, affective learning, and classroom climate. Communication Education, 56, 1-17. https://doi.org/10.1080/03634520601009710

McAndrew, F. T., \& Jeong, H. S. (2012). Who does what on Facebook? Age, sex, and relationship status as predictors of Facebook use. Computers in Human Behavior, 28, 2359-2365. https://doi.org/10.1016/j.chb.2012.07.007

McInnis, D. J., Mooman, C., \& Jaworski, B. J. (1989). Enhancing and measuring consumers. Journal of Marketing, 32-53.

Menduni, E., Nencioni, G., \& Pannozzo, M. (2011). Social network, Mondadori Educational. Milano.

Miller, J. D., \& Hufstedler, S. M. (2009). Cyberbullying knows no borders. Paper presented at the Annual Conference of the Australian Teacher Education Association (ATEA).

Muise, A., Christofides, E., \& Desmarais, S. (2009). More information than you ever wanted: Does Facebook bring out the green-eyed monster of jealousy?. Cyberpsychology and Behavior, 12, 441-444. https://doi.org/10.1089/cpb.2008.0263

Murray, K. E., \& Waller, R. (2007). Social networking goes abroad. International Educator, 16(3), 56-59.

Naaman, M., Boase, J., \& Lai, C.-H. (2010). Is it really about me? message content in social awareness streams. CSCW. https://doi.org/10.1145/1718918.1718953

Nadkarni, A., \& Hofmann, S. G. (2012). Why do people use Facebook?. Personality and Individual Differences, 52, 243-249. https://doi.org/10.1016/j.paid.2011.11.007

Nash, M. (2011). 23+ interesting Facebook infographics. Retrieved from http://ibrandstudio.com/inspiration/facebook-infographics

Nelli, R. P., \& Bensi, P. (2005). La sponsorizzazione e la pianificazione strategica, Vita e Pensiero. Milano.

Nie, N. H. (2001). Sociability, interpersonal relations, and the Internet: Reconciling conflicting findings. American Behavioral Scientist, 45(3), 420-35. https://doi.org/10.1177/00027640121957277

Orr, E. S., Sisic, M., Ross, C., Simmering, M. G., Arseneault, J. M., \& Orr, R. R. (2009). The influence of shyness on the use of Facebook in an undergraduate sample. CyberPsychology and Behavior, 12, 337-340. https://doi.org/10.1089/cpb.2008.0214

Panek, E. T., Nardis, Y., \& Konrath, S. (2013). Mirror or megaphone? How relationships between narcissism and social networking site use differ on Facebook and Twitter. Computers in Human Behavior, 29, $2004-2012$. https://doi.org/10.1016/j.chb.2013.04.012 
Pempek, T. A., Yermolayeva, Y. A., \& Calvert, S. L. (2009). College students' social networking experiences on Facebook. Journal of Applied Developmental Psychology, 30, 227-238. https://doi.org/10.1016/j.appdev.2008.12.010

Phillips, S. (2007). A brief history of Facebook. Guardian.

Pietrangelo, M. (2007). La società dell'informazione tra realtà e norma, Giuffrè Editore. Milano.

Prunesti, A. (2016). Social media e comunicazione di marketing. Presidiare la Rete, costruire relazioni e acquisire clienti innovando l'esperienza utente. Franco Angeli, Milano.

Reich, S. M. (2010). Adolescent's sense of community on MySpace and Facebook: a mixed-methods approach. Journal of Community Psychology, 38(6), 688-705. https://doi.org/10.1002/jcop.20389

Ries, T. (2010). 250 million people engage with Facebook on external sites monthly. Romanian students. A qualitative approach. Journal of Media Research, 1, 67.

Ross, C., Orr, E. S., Sisic, M., Arseneault, J. M., Simmering, M. G., \& Orr, R. R. (2009). Personality and motivations associated with Facebook use. Computers in Human Behavior, 25, 578-586. https://doi.org/10.1016/j.chb.2008.12.024

Ryan, T., \& Xenos, S. (2011). Who users Facebook? An investigation into the relationship between the Big Five, shyness, narcissism, loneliness, and Facebook usage. Computers in Human Behavior, 27(5), 1658-1664.

Saleh, F., Jani, H., Marzouqi, M., Khajeh, N., \& Rajan, A. (2011). Social networking by the youth in the UAE: A privacy paradox. Paper presented at the 2011 International Conference and Workshop on Current Trends in Information Technology, Dubai, United Arab Emirates.

Seidman, G. (2013). Self-presentation and belonging on Facebook: How personality influences social media use and motivations. Personality and Individual Differences, 54, 402-407. https://doi.org/10.1016/j.paid.2012.10.009

Sheldon, K. M., Abad, N., \& Hinsch, C. (2011). A two-process view of Facebook use and relatedness need-satisfaction: Disconnection drives use, and connection rewards it. Journal of Personality and Social Psychology, 100(4), 766-775. https://doi.org/10.1037/a0022407

Sheldon, P. (2008a). Student favourite: Facebook and motives for its use. Southwestern Mass Communication Journal, 23(2), 39-53.

Sheldon, P. (2008b). The relationship between unwillingness to communicate and students' Facebook use. Journal of Media Psychology, 20(2), 67-75. https://doi.org/10.1027/1864-1105.20.2.67

Skues, J. L., Williams, B., \& Wise, L. (2012). The effects of personality traits, selfesteem, loneliness, and narcissism on Facebook use among university students. Computers in Human Behavior, 28, 2412-2419. https://doi.org/10.1016/j.chb.2012.07.012

Steinfield, C., Ellison, N., \& Lampe, C. (2008). Social capital, self-esteem, and use of online social network sites: A longitudinal analysis. Journal of Applied Developmental Psychology, 29, 434-445. https://doi.org/10.1016/j.appdev.2008.07.002

Stern, S. R. (2004). Expressions of identity online: Prominent features and gender differences in adolescents' World Wide Web home pages. Journal of Broadcasting \& Electronic Media, 48(2), 218-243. https://doi.org/10.1207/s15506878jobem4802_4

Stutzman, F. (2006). An evaluation of identity-sharing behavior in social network communities. International Digital and Media Arts Journal, 3(1), 10-18.

Tazghini, S., \& Siedlecki, K. L. (2013). A mixed method approach to examining Facebook use and its relationship to self-esteem. Computers in Human Behavior, 29, 827-832. https://doi.org/10.1016/j.chb.2012.11.010

Thompson, J. B. (1998). Mezzi di comunicazione e modernità, Il Mulino. Bologna.

Toffler, A. (1987). La terza ondata, Sperling \& Kupfer, (trad. it) Berti L. (a cura di). La terza ondata, Sperling \& Kupfer, Milano.

Ugander, J., Karrer, B., Backstrom, L., \& Marlow, C. (2011). The anatomy of the Facebook social graph. Retrieved from http://arxiv.org/abs/1111.4503

Urban, G. (2003). Customer advocacy: is it for you? (pp. 2-3). Mit school of management, Center for E-Business. 
Urista, M. A., Dong, Q., \& Day, K. D. (2009). Explaining why young adults use MySpace and Facebook through uses and gratifications theory. Human Communication, 12(2), 215-229.

Valenzuela, S., Park, N., \& Kee, K. F. (2009). Is there social capital in a social network site?. Facebook use and college students' life satisfaction, trust, and participation. Journal of Computer-Mediated Communication, 14(4), 875-901. https://doi.org/10.1111/j.1083-6101.2009.01474.x

Valkenburg, P. M., \& Peter, J. (2008). Adolescents' identity experiments on the Internet: Consequences for social competence and self-concept unity. Communication Research, 35, 208-231. https://doi.org/10.1177/0093650207313164

Valkenburg, P. M., Peter, J., \& Schouten, M. A. (2006). Friend networking sites and their relationship to adolescents' well-being and social self-esteem. CyberPsychology \& Behavior, 9, 584-590. https://doi.org/10.1089/cpb.2006.9.584

Valkenburg, P. M., Schouten, A. P., \& Peter, J. (2005). Adolescents' identity experiments on the Internet. New Media \& Society, 7(3), 383-402. https://doi.org/10.1177/1461444805052282

Velasquez, A. (2012). Social media and online political discussion: The effect of cues and informational cascades on participation in online political communities. New Media \& Society, 14(8), 1286-1303. https://doi.org/10.1177/1461444812445877

Vollmer, C., \& Precourt, G. (2008). Always on. McGraw-Hill, USA.

West, A., Lewis, J., \& Currie, P. (2009). Students' facebook 'Friends': Public and private spheres. Journal of Youth Studies, 12(6), 615-627. https://doi.org/10.1080/13676260902960752

Wiley, C., \& Sisson, M. (2006). Ethics, accuracy and assumption: The use of Facebook by students and employers. Paper presented at the Southwestern Ohio Council for Higher Education Special Topics Forum, Dayton, OH.

Wipperfürth, A. (2005). Brand hijack: marketing without marketing. Penguin Group, New York.

Young, A. L., \& Quan-Haase, A. (2009). Information revelation and internet privacy concerns on social network sites: A case study of facebook. In Proceedings of the Fourth international conference on communities and technologies (pp. 265-274). New York: ACM. https://doi.org/10.1145/1556460.1556499

Young, K. S. (2004). Internet addiction: A new clinical phenomenon and its consequences. American Behavioral Scientist, 48, 402-415. https://doi.org/10.1177/0002764204270278

Yu, A. Y., Tian, S. W., Vogel, D., \& Kwok, R. C.-W. (2010). Can learning be virtually boosted? An investigation of online social networking impacts. Computers and Education, 55, 1494-1503. https://doi.org/10.1016/j.compedu.2010.06.015

Zhao, S., Grasmuck, S., \& Martin, J. (2008). Identity construction on Facebook: Digital empowerment in anchored relationships. Computers in Human Behavior, 24, 1816-1813. https://doi.org/10.1016/j.chb.2008.02.012

Zickuhr, K. (2010). Generations 2010. Pew Internet and American Life Project. 